In order to inform future service planning, we undertook a retrospective review of homelessness among the mentally ill admitted to an innerLondon unit with a catchment area population of 170000 of whom approximately $1 \%$ were homeless (Neville \& Masters, 1990).

The study took the form of a retrospective case note study of all admissions to the unit over a 30month period, 1 January 1992 to June 1994 inclusive. Patients were defined as being homeless or of no fixed abode if they were homeless at the time of admission and had no home to return to on discharge (Herzberg, 1987). For the purposes of statistical analysis, consultant assigned diagnoses using International Classification of Diseases (ICD-10) were summated into the broad categories of: schizophrenia, affective disorders, personality disorders, alcohol misuse, other drug misuse, other diagnoses.

A total of 133 in-patients (101 males) of no fixed abode were identified; a mean annual rate of 53 per year, or $11 \%$ of all admissions annually. Eighteen $(18 \%)$ males and $9(28 \%)$ females were referred by the police; $9(9 \%)$ males and no females were admitted via the prison services. Twenty-seven (27\%) males and 11 (34\%) females of no fixed abode were detained under the Mental Health Act (1983).

Mean age of no fixed abode patients on admission was 33 years (s.d.11) and was similar for both genders. Some $80 \%$ of both males and females of no fixed abode had never been married: $53(52 \%)$ males and $18(56 \%)$ females had contact with a family member within the previous year and $2(2 \%)$ males and no females were currently employed. Approximately onethird of males and females were currently registered with a general practitioner.

The diagnostic profiles of males and females were strikingly similar: schizophrenia was the most common diagnosis, $42(42 \%)$ males and 10 (34\%) females; followed by alcohol misuse in the case of males, $19(19 \%)$ and both alcohol misuse and personality disorders in the case of females - each accounting for 5 (16\%). Affective disorders accounted for a further $13 \%$ in both sexes. Diagnosis was not available in $9 \%(9$ males and 3 females).

In the unit under study, the proportion of inpatients who were of no fixed abode was of a high order and in keeping with a recent report from a catchment area of similar demographic characteristics (Neville \& Masters, 1990). Similar to previous studies, schizophrenia was the most common diagnosis (Berry \& Orwin, 1966; Herzberg, 1987). Contrary to Herzberg's findings (1987), there was little evidence that females were socially more stable than males.

Community psychiatry faces a further challenge in meeting the needs of this small but substantial subgroup of vulnerable patients.
BERRY, C \& Orwin, A. (1966) No fixed abode: a survey of mental hospital admissions. British Journal of Psychiatry, 112. 1019-1025.

HERZBERG. J. L. (1987) No fixed abode: a comparison of men and women admitted to an east London psychiatric hospital. British Journal of Psychiatry, 160, 621-627.

Nenile. M. \& MASTERS, D. (1990) A Report of Inpatient Activity on Mental Illness Wards at Guy's Hospital for the Full Year 1989. London: Lewisham and North Southwark Mental Health Executive.

MIRIAM O'DOHERTY, St Vincent's Hospital, Convent Avenue, Richmond Road, Dublin 3; VIV MAK and MARIOS PIERIDES, Lambeth Healthcare NHS Trust, Landor Road, London SW9 9NT

\section{High dose antipsychotic medication}

Sir: The findings of Sillifant et al (Psychiatric Bulletin, October 1997, 21, 612-617) that four out of 11 patients on high dose antipsychotic medication have low white cell counts should not cause alarm or surprise. A large-scale survey by Pisciotta (1971) of patients taking phenothiazines was reported 26 years ago. Of 6200 patients, 2000 developed moderate leukopenia. This was found to be a transient phenomenon. These results may help to alleviate the anxiety caused by minimally abnormal results reported by Sillifant and her colleagues.

Pisciotta, V. A. (1971) Drug-induced leukopenia and aplastic anaemia. Clinical Pharmacology and Therapeutics, 12, 13-43.

J. WAITE, Consultant Psychogeriatrician, Nottingham Healthcare NHS Trust, Health Care of the Elderly, The Courtyard, East Block, University Hospital, Nottingham NG7 $2 U H$.

\section{Definition of 'haltlose'}

Sir: While involved in the undergraduate teaching programme in psychiatry, I was asked by one of my students to explain the term 'haltlose' as it appears in the ICD-10 Classification of Mental and Behavioural Disorders (World Health Organization, 1992). This term can be found in the category of 'Specific Personality Disorders' (F60) where it is included under the heading of 'Other Specific Personality Disorders' (F60.8). This rubric is used to classify: 'A personality disorder that fits none of the specific rubrics F60.0 F60.7', and includes the terms: eccentric, 'haltlose' type, immature, narcissistic, passiveaggressive, and psychoneurotic personality (disorder). While the other terms in this rubric are in relatively common usage, I was not clear as to the meaning of the term 'haltlose' as used in psychiatric practice or otherwise.

A literature search was then carried out, however there were no records of 'haltlose' on 
any of the databases searched, including: ClinPsych (1980-1996), Excerpta Medica Neurosciences and Psychiatry (1986-1996) and Medline (1966-1996). None of the psychiatric dictionaries available to me provided any explanation of the term, neither was it mentioned in a number of dictionaries of English. The word 'haltlos' (which has no terminal ' $e$ ') is to be found in a dictionary of the German language where it has several meanings including 'insecure', 'unrestrained', 'groundless' and 'unfounded', and I wonder if any of these is the intended explanation of the term.

To date I have not received a reply from the Division of Mental Health of the World Health
Organization, to whom I have addressed my query, however in view of the level of unfamiliarity with the term I wonder if it is, in fact, used or useful in other countries and whether a more familiar term describing the same personality disorder would lead to its increased use?

World Health Organization (1992) The ICD-10 Classification of Mental and Behavioural Disorders: Clinical descriptions and diagnostic guidelines. Geneva: WHO.

Rachael Cullivan, McDonagh Research Fellow in Psycho-Oncology, Department of Psychiatry, St Camillus Unit, St Vincent's Hospital, Dublin 4, Ireland

\section{Recent Council Reports}

CR47 College policy statement on rape, $£ 7.50$

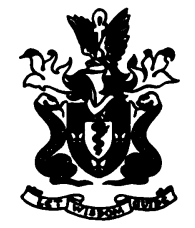

CR48 Report of the Working Party to review psychiatric practices and training in a multi-ethnic society, $£ 5.00$

CR49 Consensus statement on the assessment and investigation of an elderly person with suspected cognitive impairment by a specialist old age psychiatry service, $£ 5.50$

CR50 'Wish you were here'? Ethical considerations in the admission of patients to substandard psychiatric units, $£ 2.50$

CR51 The Responsiblities of Consultant Psychiatrists, $£ 5.00$

CR52 Sexual Abuse and Harassment in Psychiatric Settings, $£ 5.00$

CR53 Assessment and clinical management of risk of harm to other people, $£ 3.00$

CR54 Chronic fatigue syndrome, $£ 10.00$

Available from the Publications Department, Royal College of Psychiatrists, 17 Belgrave Square,

London SW1X 8PG (Tel. +44(0)171 235 2351, extension 146). The latest information on College publications is available on the INTERNET at: http://www.demon.co.uk/rcpsych/ 